\title{
MODELS FOR LEADERSHIP IN CURRICULAR INNOVATION: CONCORDIA'S CENTRE FOR ENGINEERING IN SOCIETY
}

\author{
Govind Gopakumar, Deborah Dysart-Gale, Brandiff Caron, and Robin A.L. Drew \\ Faculty of Engineering and Computer Science, Concordia University \\ govind@encs.concordia.ca, bcaron@encs.concordia.ca
}

\begin{abstract}
This paper provides an overview of emerging trends in Innovative engineering pedagogy incorporating interdisciplinary ventures in universities. These trends encompass both pedagogical philosophies and institutional modes of delivery. We examine similar models across North America, with special reference to the Canadian context. We conclude with a case study of Concordia University's Centre for Engineering in Society (CES), a small academic unit of interdisciplinary humanities and social science scholars housed within the Faculty of Engineering and Computer Science and staffed by disciplinary experts working together with engineers; CES presents a unique model in Canada.

The CES model offers some promising opportunities for engineering education as it pursues its mission to articulate the difference between the competent technician and the professional as citizen and leader who pilots the technological trajectory of society. The presence of non-engineering faculty members leads to interdisciplinary research and collaboration, improved integration of risk, social impact and equity assessment in curricular and project design, and innovation in addressing CEAB graduate attributes. CES also presents a neutral space for activities that cross engineering and computer science boundaries, in particular collaborative global engineering projects, humanitarian engineering, and groups such as Engineers without Borders. Challenges include faculty and students indifference to non-technical subject matter, inability to negotiate critical studies of technology, and a tendency for marginalization of faculty without technical expertise.
\end{abstract}

Keywords: engineering education, society, interdisciplinary, Canada

\section{INTRODUCTION}

Undergraduate engineering curriculum has typically sought to assemble four major avenues - knowledge in engineering and physical science, ability to formulate and analyze complex engineering problems, skill in using analytical tools and techniques, and finally, creativity to design solutions as processes or products. Depending on program architecture, courses from these primary streams are ordinarily augmented by a restricted selection of humanities, social science and management courses to round up their education in engineering. Nevertheless, the prime assumption within such a curricular trajectory is that acquisition of technical skill and knowledge is critical for a career in engineering [1]. Seen from this perspective, technical competencies are what define success in the engineering profession, and the leading mission of engineering education is the transmission of an adequate quantum of technical abilities.

Yet, contemporary engineering practice and leadership around the world is ordered as a profession, and as such, requires a knowledge base and expertise that extends beyond technical competencies [2] and [3]. A profession as a specific form of collective organization of humans is inseparable from two aspects - an articulation of a vision and an appropriate set of practices and relations. The vision of the profession, understood through the collective aims, values and goals of the body, builds its normative architecture. This normativity prescribes not only proper professional activities but also proper means to achieve its ends. This latter part in turn requires an organization of social relations, a specification of roles and responsibilities, and an appropriate set of practices that govern how individual engineers act within the profession. Acknowledging the social constitution of engineering practice, engineering curricula around the world have responded by introducing courses on professionalism and engineering ethics that initiate students to the definite social and ethical expectations of their profession.

A factor that continually encroaches on how engineers engage with society is the shifting pull exerted by changing societal needs. As a result, engineers have had to continuously adapt and respond to the varying demands placed on them, generating several calls for a "complete engineer" [4], a "holistic engineer" [5], or a "flexible or adaptive engineer" [6] and [7] who combines wellgrounded technical skills with an agile social praxis. Along similar lines, differences in engineering practice, 
and international and regional social disparities and inequities have generated a number of proposals to promote awareness of humanitarian engineering [8], internationalization [9], and social justice and engineering [10] and [11]. More recently, globalization, as the transnational flows of humans, information, technology, capital, and jobs, has become a placeholder for a whole range of proposals for curricular innovations such as the globally competent engineer [12] and [13].

Against this context, this paper seeks to understand the significance of Concordia University's Centre for Engineering in Society (CES) as an interdisciplinary academic venture within engineering education. Of particular interest are two questions: first, what are some existing models in North America for creatively linking engineering education with wider social, ethical and policy affairs; second, what are some challenges and opportunities for CES and for engineering education in Canada as this venture evolves? Using qualitative data, this paper offers preliminary observations that could form the basis for future research into the intersection between engineering education and society.

\section{INTERDISCIPLINARY MODELS}

The United States is the major locus of the renewed attention to diversifying the nature of professional competencies needed for engineering leadership in society [14], [15] and to a lesser extent, Europe (there has been far less attention in Canada, in comparison). In the United States, the restructuring of undergraduate engineering education has been accompanied by calls for greater breadth and flexibility in the curriculum [16], [17] and [18]. Three reasons are proposed for this curricular shift 1. In comparison to other professions that base their graduate level professional training on a liberal undergraduate degree, engineers are produced through a rigorous, uni-dimensional education with limited curricular scope; 2. American engineers need additional dimensions of knowledge in order to excel in technical innovation in a globally-competitive world; 3. Finally, greater flexibility in education is required to facilitate the entry of ethnic and racial minorities and women into the profession [16].

In this atmosphere of reflection, experimentation and uncertainty, there has been renewed attention to some innovative interdisciplinary models that engage with engineering education and seek to broaden curriculum by injecting a host of themes that complement and enrich the educational experience of students. These themes have ranged from globalization, international development, sustainable development, product design, ethics, public policy, and arts. Another factor common across these ventures is the presence of full-time academic faculty from the humanities and social sciences who are skilled in interdisciplinary education for engineering students. In other words, these efforts are spearheaded by qualified personnel who excel at engaging students in the complex relation between engineering and society. In colleges of engineering and engineering universities across the United States, especially in the more prestigious and selective schools, such experimentation with curriculum has become the norm. While each experimental endeavor must be understood within the specific institutional context of the university and engineering faculty, it is possible to describe some generalizable models across such ventures. These models share some general organizational relations between different academic units that are involved in the venture. Each model also is unique in terms of research, curricular and programmatic offerings, and role and status within the engineering faculty. Three models are presented here:

a. Service department model,

b. Integrated department model, and

c. Faculty enrichment model.

Each of these models is described in detail below.

\subsection{Service Department Model}

As the name suggests, in a service department model, the interdisciplinary venture is usually located within the Faculty of Engineering as a service department - a status that differentiates it from the standard departments that constitute the faculty (Fig. 1). The service department is typically the initial demonstration of purpose by the faculty to initiate a process of transformation in its educational mission. As a service department, the academic unit fulfills a specific mandate that arises from, and is vital to the evolving vision, objectives and interests of the faculty. Typically, this mandate is exercised by teaching courses required for undergraduate students in the faculty. This teaching role comes to define the unit in the sense that the departmental identity is expressed by its service to the faculty. Faculty members in the service department are involved in their individual research careers by publishing papers, books, establishing laboratories and attending conferences, but the collective identity of the department is tied to the topical nature of the courses it offers or specialized certificates it offers. Two examples of this model are provided by Pennsylvania State University, University Park campus by the Science, Technology and Society program (http://www.sts.psu.edu/), and by the School of Engineering Design, Technology and Professional Programs (http://www.sedtapp.psu.edu/index.php). The SEDTAPP is housed within the College of Engineering at Penn State and offers courses and minors in interdisciplinary design, humanitarian engineering, leadership and entrepreneurship. An advance on this 
model is the Department of Science, Technology and Society (STS) located in the School of Engineering and Applied Sciences at the University of Virginia. (http://www.sts.virginia.edu/). In this particular case, the STS department began its existence solely as a service department dedicated to providing instruction to engineering students on the social and ethical dimensions of technology, but has now evolved into a more coherent, integrated department with a mission that extends and develops its service.

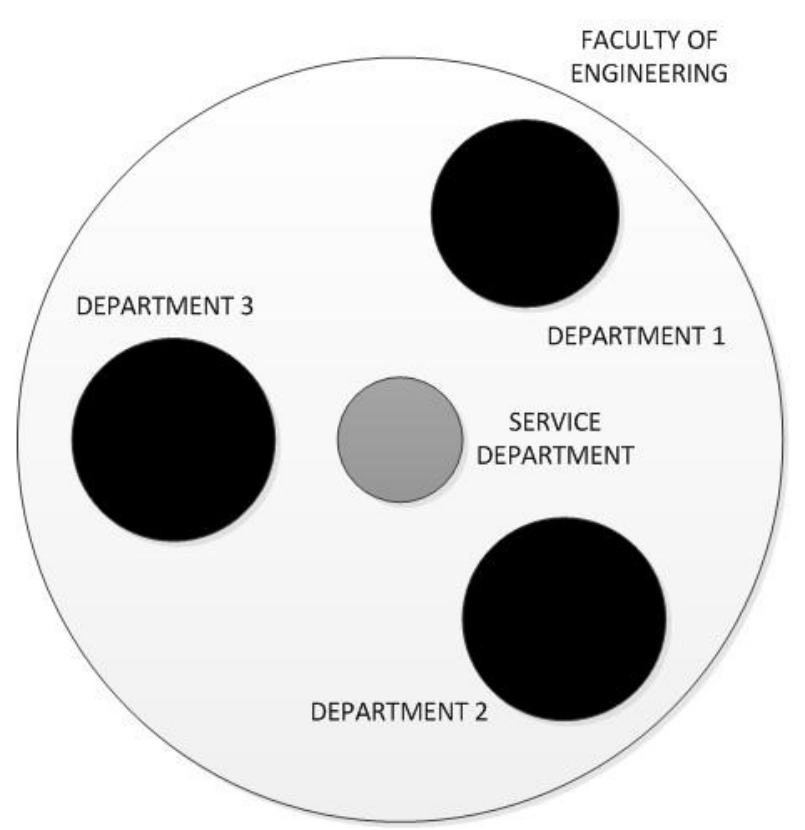

Fig. 1. Service Department Model.

\subsection{Integrated Department Model}

In the Integrated Department model, the academic unit has acquired the status of a full-fledged department and in doing so has evolved a fully-formed identity for itself within the faculty (Fig. 2). The Integrated Departmental Model is an advance over the Service Department model. The service department may evolve a specific assortment of skills and capabilities that allow it to integrate fully into the faculty of engineering and its curricular and educational contributions, in alignment with the evolving mission of engineering education at large. However, two attributes are necessary for an experimental unit to be acknowledged as fully integrated in the faculty - first, generation of engineering knowledge; and second, reproduction of the generated knowledge. The first step of is crucial because by generating knowledge that advances engineering practice, the department is accorded an equivalent standing in the faculty. Although the integrated department may extend course offerings to meet its service obligations to the faculty, it is no longer defined by them. The courses offered by the unit are accepted in league with offerings of any other department. The second attribute of initiating the reproduction of knowledge is achieved when the unit develops an autonomous mandate in education at the undergraduate and graduate levels, especially through a Ph.D program. Developing a Ph.D. program not only marks the culmination of the process of reproducing knowledge and also often heightens the unit's integration.

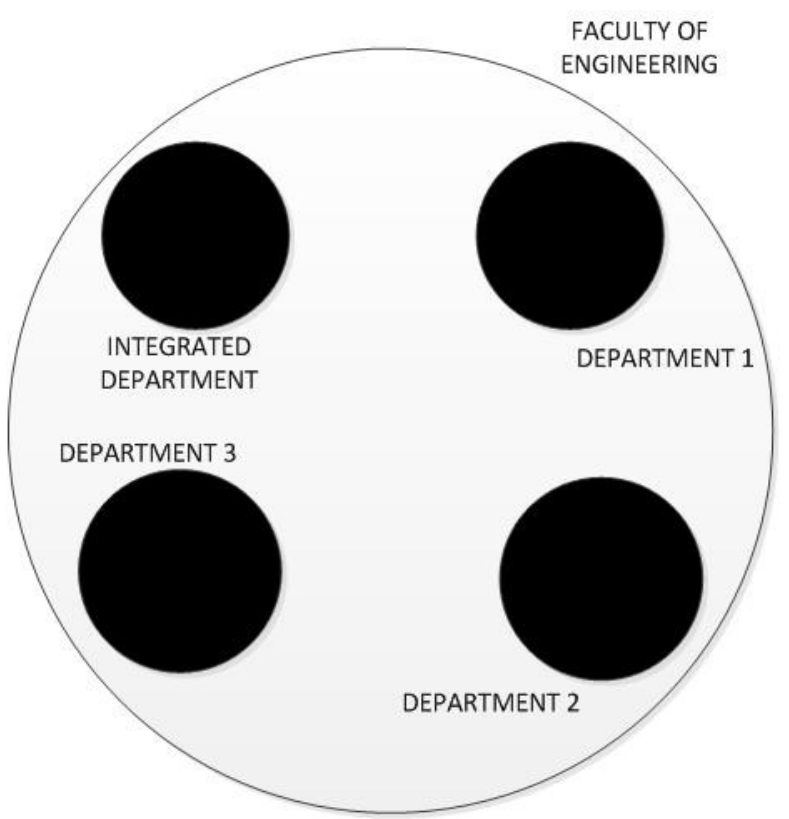

Fig. 2. Integrated Department Model.

Three examples of the Integrated Department model are the Department of Technology \& Society located in the College of Engineering and Applied Science at SUNY Stonybrook (http://www.stonybrook.edu/est/index.html), the Engineering Systems Division at MIT (http://esd.mit.edu/), and the Department of Engineering and Public Policy in the Carnegie Institute of Technology at Carnegie Mellon University (http://www.epp.cmu.edu/). Each of these departments identifies itself as similar in every way to the standard departments that constitute their colleges of engineering. In addition, these programs possess graduate (and/or undergraduate) programs that culminate in an interdisciplinary Ph.D. program.

\subsection{Faculty Enrichment Model}

The final model, Faculty Enrichment, is again an advance over the service department model. With time, the service department acquires adequate skill and capacity to propose and execute unique undergraduate or graduate training programs in collaboration with existing engineering departments. These unique, joint programmatic offerings enhance and enrich the nature of education experience delivered by the faculty. Through 
such an arrangement also the department grows beyond its service mission and acquires instead the role of delivering programs that enrich the educational experience. As an asset to the college of engineering, the unit begins offering dual degree programs or joint/collaborative efforts with other engineering departments at the undergraduate/graduate levels. The national success of these unique curricular offerings becomes a selling point for not only the department but also the faculty itself.

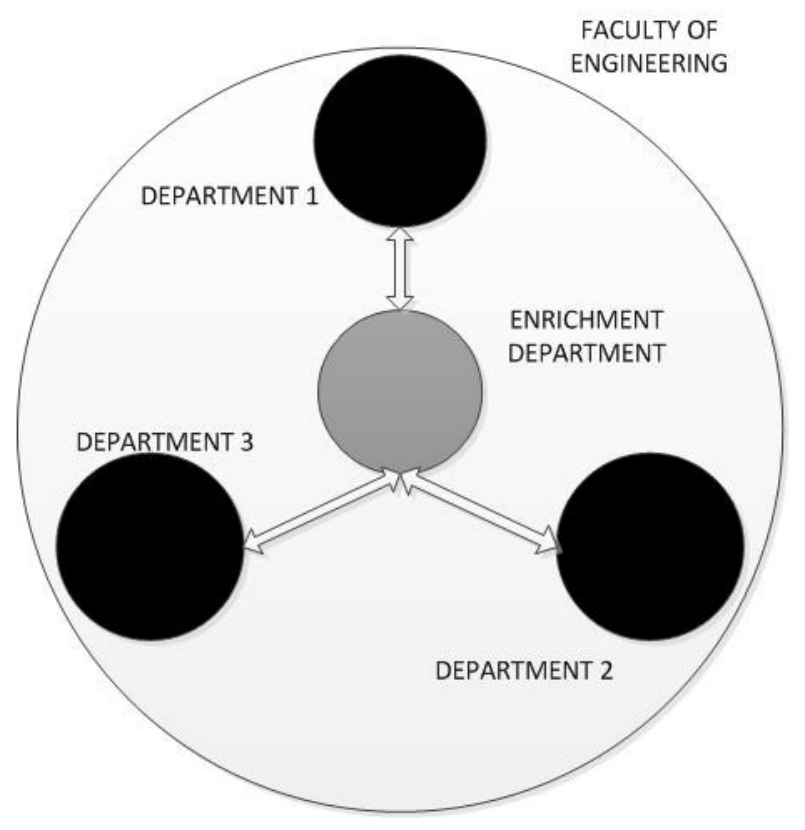

Fig. 3: Faculty Enrichment Model

An example is the Department of Science and Technology Studies (STS) at Rensselaer Polytechnic Institute (http://www.sts.rpi.edu/). The department offers a unique interdisciplinary design training experience for undergraduate mechanical engineering and computer science students that is called Design, Innovation and Society. This program offers a series of design studios that are co-taught by faculty members in mechanical engineering/computer science and the STS department. The Design, Innovation and Society program is administered by the Science and Technology Studies program, but faculty members in mechanical engineering and in computer science jointly supervise the program structure and student experience. The national recognition that the Design, Innovation and Society program has received (evidenced by its success in placing alumni in prestigious firms, or graduate schools of design) testifies to the value of training engineering students to be sociallyreflective design practitioners, but more importantly it becomes a channel to demonstrate the value-addition a program like this can bring in the contemporary world.

\section{CENTRE FOR ENGINEERING IN SOCIETY}

Centre for Engineering in Society (CES) is a small academic unit housed within the Faculty of Engineering and Computer Science in Concordia University, Montreal. The unit is staffed by humanities and social science scholars whose primary duty within the faculty has been to teach courses that fulfill Canadian Engineering Accreditation Board (CEAB) mandated requirements for complementary curriculum as well as content of several graduate attributes.

\subsection{Mission}

The precursor of the CES was established within the Faculty of Engineering and Computer Science in 2005. In 2011, as part of a process of expanding its mission of educating engineers and researching engineering education, the unit assumed its identity as the Centre for Engineering in Society. A distinct contribution of the centre to the faculty is "broadening the scope of graduate and undergraduate education, and preparing students to take their place as citizens, researchers, innovators, and stewards of the public good" [19]. A key route CES recommends to achieve this goal is through complementary studies in engineering education.

\subsection{Complementary Studies}

Complementary studies, as the name suggests, is a proposal for a structured plan of study in engineering education that complements the central task of acquisition of technical skills and knowledge in important ways. This approach arises from a commitment to equipping future engineers with the skills to appreciate technology and engineering as positioned inextricably within a complex, interconnected social domain. Thus, in order to perform within this interrelated technological and social environment, engineers require some minimal skills that complement the core technical skills they need.

Currently, CES sees a dual role for itself in operationalizing complementary studies in the engineering curriculum - first, a normative role, and second, a service role. In its normative role CES seeks to craft professionals from technologists. While a technologist is a person who is adept at solving technological problems, a professional is a thought leader who pilots the technological trajectory of society. The distinction between the two is vast and hinges on leadership qualities. While the technologist is comfortable retreating into a technological domain, the professional is immersed in society even as s/he engages collaboratively with different social actors. Complementary studies provide the tools to construct this societal leadership. CES' service role is fulfilled by the 
courses that CES administers for the faculty. These courses such as technical communication, impact of technology in society, engineering ethics, and professionalism contribute directly to meeting $\mathrm{CEAB}$ graduate attributes.

\section{EMERGING TRAJECTORIES}

Stemming from the discussion on interdisciplinary models earlier in this paper, it is necessary to inquire into possible emerging pathways that could result from the complementary studies emphasis CES has assumed within the engineering faculty. The service orientation within the complementary studies identifies CES closely with the Service Department Model (Fig 1). In this role CES has a mission that is defined by the service it extends to the faculty - teaching courses that contribute to meeting CEAB graduate attributes. As in the service department model, it is this teaching role that has come to define the identity of the department.

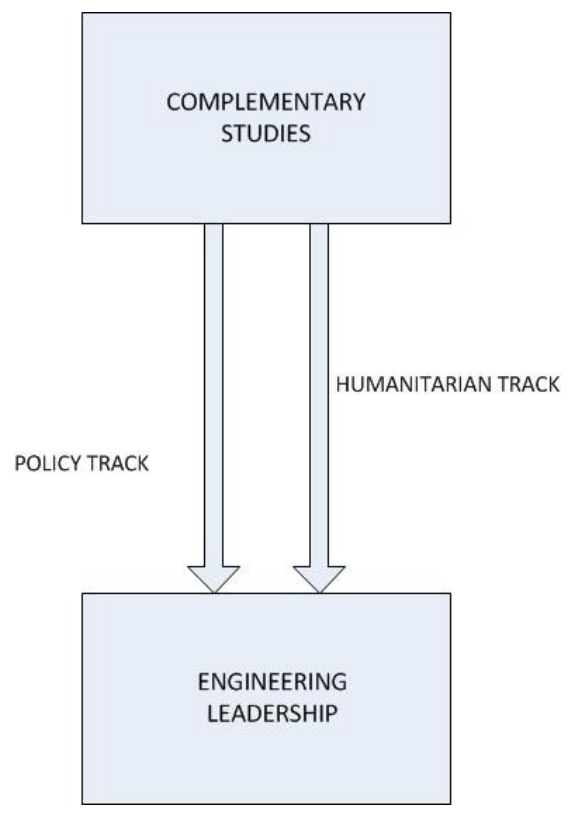

Fig. 4: Emerging Pathways in Engineering Leadership

As CES continues to evolve and advance, the unit will necessarily have to envision a change trajectory for transforming itself. The integrated department model and the faculty enrichment model offer two distinct trajectories of change that the CES can adopt. By adopting an integrated department model, CES would generate engineering knowledge and then reproduce this knowledge through graduate programs. On the other hand, a faculty enrichment model would suggest the importance of establishing collaborative models with existing departments in order to develop educational experiences that retain the possibility of enrichment. At the heart of the choice between the models for CES is to transform its focus on complementary studies either towards engineering knowledge or towards faculty enrichment. Given the nature of the curriculum currently provided by CES through complementary studies (and the expertise of its faculty members), the faculty enrichment model holds out exciting possibilities.

One possible strategy of faculty enrichment is presented here (Fig. 4). The evolution of complementary studies towards engineering leadership provides an interesting avenue for enriching engineering curriculum. Two parallel tracks of complementary engineering leadership are proposed here - a policy track and a humanitarian track. The policy track provides students with courses that analyze technology-society issues with the aim of informing public policy decisions. The humanitarian track, on the other hand, provides students with the skills and tools needed to manage, advocate, and lead development or reconstruction efforts around the world. These tracks could be operationalized through a coherent course sequence leading to a certificate in engineering leadership.

\section{CONCLUSION: CHALLENGES \& OPPORTUNITIES}

Regardless of the model adopted by CES in the long term, it is significant that it "began life" within the service model. Implicit in its creation under this model was the belief that the understanding the concerns and content of social science and humanities is important for progressive, professional engineering practice, but also that the teaching of such material was beyond the academic scope of most engineering and computer science faculty. Several challenges for CES lurk within this relationship. On one hand, engineering students, among the best prepared and most gifted in any university, are frequently intrigued by the content of complementary courses and readily grasp the importance of the role of expert and public leader in social debates concerning technology policy. On the other hand, their enthusiasm may be dampened by dominant discourse that marginalizes such discussion as peripheral to "real" (i.e., technical) engineering courses.

As societies' technogenic problems increase, and with it, the need for engineers to contribute their expertise to thoughtful solutions, it is hoped that academic and practicing engineers will gain increasing interest in the area of complementary engineering studies, and become involved in the establishment of interdisciplinary ventures within the faculty enrichment or integrated model. This will open new horizons for interdisciplinary research and curriculum. The fate and future of such ventures as CES 
depends on the evolution of engineering educators' conceptualization of the role of the engineer in society.

\section{References}

[1] Dominico Grasso, "Engineering a liberal education," Prism, vol. 12 , no. 2, pp. 76, 2002.

[2] Sharon Beder, "Beyond Technicalities: Expanding Engineering Thinking," Journal of Professional Issues in Engineering Education and Practice, vol. 125, no. 1,pp. 1218, 1999.

[3] Denis Lemaitre, Raymond Le Prat, Erik De Graaff, and Ludovic Bot, "Editorial: Focusing on competence," European Journal of Engineering Education, vol. 31, no. 1, pp. 45-53, 2006.

[4] Erik De Graaff and Wim Ravesteijn, "Training complete engineers: Global enterprise and engineering education," European Journal of Engineering Education, vol. 26, no. 4, pp. 419-427, 2001.

[5] Dominico Grasso and Melody B. Burkins (eds.), Holistic Engineering Education. New York, NY: Springer, 2010, $301 \mathrm{pp}$.

[6] Juan Lucena, "Flexible Engineers: History, Challenges, and Opportunities for Engineering Education," Bulletin of Science Technology \& Society, vol. 23, no. 6, pp. 419-435, 2003.

[7] Jonathan D. J. Vandersteen, “Adaptive Engineering," Bulletin of Science Technology \& Society, vol. 31, no. 2, pp. 134-143, 2011.

[8] Jonathan D. J.Vandersteen, Carolyn A. Baillie, and Kevin R. Hall, "International Humanitarian Engineering: Who Benefits and Who Pays?," IEEE Technology and Society Magazine, vol. 28, no. 4, pp. 32-41, 2009.

[9] Darlene Bremer, "Engineering the World," Online Journal for Global Engineering Education, vol. 3, no. 2, 2008.

Available as of April 21, 2012 from

http://digitalcommons.uri.edu/ojgee/vol3/iss2/

[10] Dean Nieusma and Donna Riley, "Designs on development: engineering, globalization, and social justice," Engineering Studies, vol. 2, no. 1, pp. 29-59, 2010.
[11] Jen Schneider, "Engineering and the value of social justice," Engineering Studies, vol. 2, no. 1, pp. 1-4, 2010.

[12] Gary L. Downey, Juan C. Lucena, Barbara M. Moskal, and Rosamond Parkhurst, "The Globally Competent Engineer: Working Effectively with People Who Define Problems Differently," Journal of Engineering Education, vol. 95, no. 2, pp. 107-122, 2006.

[13] Peggy Blumenthal and Ulrich Grothus, "Developing global competence in engineering students: US and German approaches," Online Journal for Global Engineering Education, vol. 3, no. 2, 2008. Available as of April 21, 2012 from http://digitalcommons.uri.edu/ojgee/vol3/iss2/

[14] James J. Duderstadt, Engineering for a Changing World: A Roadmap to the Future of Engineering Practice, Research and Education, Ann Arbor, MI: University of Michigan. Available as of April 21, 2012 from:

http://milproj.ummu.umich.edu/publications/EngFlex report /download/EngFlex\%20Report.pdf

[15] National Academy of Engineering, Educating the engineering of 2020: Adapting engineering education to the new century, Washington, DC: National Academies Press. Available as of April 21, 2012 from: http://www.nap.edu/catalog.php?record_id=10999\#toc

[16] C. Judson King, "Restructuring Engineering Education," Journal of Engineering Education, vol. 101, no. 1, pp. 1-5, 2012.

[17] Karan Watson, "Change in Engineering Education: Where Does Research Fit?," Journal of Engineering Education, vol. 98, no. 1, pp. 3-4, 2009.

[18] John Bransford, "Preparing People for Rapidly Changing Environments," Journal of Engineering Education, vol. 96, no. 1, pp. 1-3, 2007.

[19] CES, "Mission," Available as of April 21, 2012 from: http://www.encs.concordia.ca/ces/mission/ 